\title{
Evaluation of Consumer Buying Behavior for Specific Food Commodity using Fuzzy AHP approach
}

\author{
G.N.Patel
}

\section{Introduction}

Among the various inspiring guidance of buying behavior that scholars have promoted over the years, the conception of a need for consideration has been a usual theme (Hansen 1972, Howard and Sheth 1969, Sheth et al. 1991). Consumer behavior has been a long standing work of discussion in various fields. Behavior of the consumer have always been assumed as a strong component to be researched for strong exploratory aspect of choice making for different products (Cox1967), accepting new product(Mittelstaedt et al. 1976), price (Venkatraman ,1990), browsing ((Bellengar and Korganokar 1980) and seeking information either through catalogues or talking to others about their purchase (Price and Ridgway, 1982). In 1998 Belch questioned the habit of using and discarding the products or services, so that the positioning of the product can be improved in the mind of consumer.

Since 1950s, majority of studies held in the field of consumer decision making process with the prime objective of understanding the detailed and methodical buying process (Howard, 1994). The literature on consumer behavior has constructed upon two major assumptions first, consumers are more inclined towards various factors which influence them like

(a) Environmental effect-social class, family, culture ,personal effect and other

(b) Individual effect- motivation, involvement, knowledge, attitude, personality, lifestyle and others

(c) Psychological effect-behavior change, learning information process and others

And, second is that consumer is a sensible decision maker who is capable to go through chronological process of decision making and take the prime decision amongst the options available in the market.

\section{Consumer Behavior}

Kolb in 2006 and Siwach and Dahiyain 2009 focused on the level of participation of consumer, as it is a complex process. Nicosia in 1966, Engel et al. in 1968 and Howard and Sheth in 1969 all have contributed three major models regarding the decision making process of consumer. These models tried to find out the psychosomatic state of consumers from the point of awareness 
of a particular option for satisfying his/her need to the ultimate assessment. And this process is assisted by a sequence which involves exposure, consideration, understanding recognition and maintenance. Though the process explained by all authors differ in delivery but the five stage process is common in all the models (Mitchell and Boustani 1993). And the five stages are Recognition of need, Search for Information, Evaluation of Alternatives, Purchase decision and Post - purchase outcomes.

Primarily, the consumer makes attempt to find out the commodity as per the aroused need and later buy the commodity that assure the maximum satisfaction. And this decision from the stage of need arousal to purchase decision was supported by various factors like availability of product, recommendations from friends/relatives/retailer, quality, brands, price and many more. Actually consumer behavior is the subgroup of human behavior that anxiously deals with the choices, and actions made by people while selecting and consuming the product which leads to the fulfillment of need.

The marketer pays lots of attention in measuring the behavior in all aspects from who buys the product? , How they buy?, Where do they buy? , How often they Buy?, and more such. These questions only helps in understanding the most influential factor involved in decision making. But this study is focused on the five stages of consumer behavior, in view to find out at which stage of consumer behavior model, consumers spends the maximum time to take final decision of buying the product out of the choices.

As we have entered into a competitive world, we can see various variations and expansion occurring in all the industries and marketers are trying to keep their momentum with dissimilar needs of the consumer. However, since past customer is always treated as KING and all actions have been designed to make him please. As, now a day's market is engulfed with numbers of products. So, the challenge each marketer is facing is to understand the range of consumer behavior and offering them goods and services accordingly. The image of the company now a days is constructed by its customer. Thus, the achievement of the company will be decided by how effectively marketers have achieved the assorted needs of consumer and made a life time association with them(Nair 2004).Marketers have to grasp what consumer needs as it will have direct impact to the profitability of a company(Assael 2001).The specific reasons that marketers should analyze the complex characteristics of consumer is that consumer has more knowledge about the market than ever before and can well trace the best product, best offer, best distribution channel very easily .The study of consumer behavior delivers calculated facts about the basic desires of customer and helps in designing the impulsive marketing program. Consumer behavior during various stages of getting, consuming and positioning of a product is well understandable by accepting the issues like thinking psychology of consumer, reasons to feel the product, and selecting between different alternatives.

The limitations in having complete knowledge about consumer or handling customer data will affect the outcome of the market. Therefore, it is essential to understand for the marketers that 
which strategy will work to retain the customer. Thus, this study is to move towards pair-wise comparison of the five stage of consumer behavior to assess the weights of Information Stage (IS), Evaluation Stage(ES) and Purchase Stage(PS). With this aim, a comparative analysis of the results was done focusing particularly on use of fuzzy analytical hierarchy processing (FAHP), to identify the most important stage of consumer behavior that determines the preference towards specific food commodity by Indian consumers.

\section{Information Stage}

Consumer seeks information, at this stage like availability of different brands, price of all available brands, function, utility and many such features related to the type product he/she wants to purchase. The major finding at this stage for the consumer is the various alternatives available in the market to satisfy the desired need.

\section{Evaluation stage}

Once the information is collected, it's the time to find out the best out of the alternatives available in the market on the basis of quality, purity and many other criteria. At this stage consumer shortlist the brand as per his/her requirements and eliminates the other brand. This phase involves comparison of different criteria's which will lead to the final purchase decision.

\section{Purchase decision Stage}

In 1992, Lillien et.al. explained that consumer only rank his/her preference for the different alternatives and purposely buy the product which suits to them, from the alternatives.

\section{Analytic Hierarchy Process}

The Analytic Hierarchy Process (AHP) is a multi-criteria decision-making approach, introduced by Saaty (1980). AHP classifies the basic level by breaking down the problem into its smaller essential quantities. AHP is mainly appropriate for multifaceted choices which include the comparison of factors which are elements which are difficult to compute. The core of AHP is to get the relative weights to the decision alternatives.

Then all the elements are first compared in corresponding level and $(n \times n)$ pairwise comparison matrix was formed where $A=\left(a_{i j}\right)$ for all i, j $=1,2 \ldots, \mathrm{n}$ which represents a pairwise comparison square matrix, $\left(a_{i j}>0\right)$ provide the importance of one element over the other and diagonal elements are equal to 1 and other elements are just the reciprocal of the importance given earlier.

Priority vector is derived from following process: 


$$
\begin{aligned}
& a_{i j}^{\prime}=a_{i j} / \sum_{i=1}^{n} a_{i j} i, j=1,2, \ldots n \\
& w_{i}=\left(\frac{1}{n}\right) \sum_{j=1}^{n} a_{i j}^{\prime}, i=1,2, \ldots, n
\end{aligned}
$$

The next step is to check the consistency of the comparative preferences of choices and alternatives. As few decision problems are qualitative in nature and it is difficult to allocate exact weights of preferences because decision makers may or may not always be capable of answering logical. While producing weights a decision maker may form repetition of comparisons owing to poor decisions or uncertainty. These repetitions cause numerical error. AHP accepts an inconsistency proportion of less than $10 \%$ in consideration of the different elements of criteria and goals. To check the consistency index (CI), Consistency Ratio (CR) and largest Eigen value $\lambda_{\max }$ ofA are calculated as:

$$
\lambda_{\text {max }}=\sum_{i=1}^{n} \sum_{j=1}^{n} a_{i j} w_{j}
$$

$$
C I=\left(\lambda_{\max }-n\right) /(n-1) C R=\frac{C I}{R I} \quad, \quad R I \quad \text { being the random consistency index is used. }
$$

The CR ranges as per the size of matrix that is 0.05 for a 3 by 3 matrix and 0.1 for all larger matrices, where $n \geq 5$.If $\mathrm{CR} \leq 0.1$ it indicates good level of consistency which indicates that the estimate within the matrix is tolerable. And if $\mathrm{CR} \geq 0.1$ there is inconsistency of judgment and there is a need to review the evaluation process.

The weights calculated for IS, ES and PS are $(0.300,0.390,0.310)$ respectively where $\lambda_{\max }=4.2763$ And $\mathrm{CR}=0.9633$. As explained earlier, the decision is acceptable as long as $C R \leq 0.1$. If CR larger than 0.1 , the decision maker should re-check his decision.

\section{Fuzzy sets and fuzzy number}

A number of multiple-criteria decision methods have been introduced, studied and established since 1970s like regression, Delphi method, balance scorecard, Data Envelopment Analysis, Analytical Hierarchy Process, Fuzzy Analytic Hierarchy Process and many more. After evaluating the aim, advantage and disadvantage and basic concept of all the methods, we discovered Fuzzy Analytic Hierarchy Process as the best suited method to our problem, because of the complication and ambiguity faced by the decision maker where traditional Analytic Hierarchy Process involve crisp judgments, fuzzy judgments provide more confident results. 
Number of approaches have been established for handling fuzzy comparison matrices like fuzzy logarithmic least squares method submitted by Van Laarhoven and Pedrycz (1983) to acquire triangular fuzzy weights modified later by Wang et al. 2006 . Many other approaches of fuzzy have been defined by various authors and implemented in various applications. Chang in 1996 recommended how crisp weights can be developed through extant analysis approach. Because of simple calculation and process, extant analysis approach was used by various researchers in number of applications (Bozbura F.T. et al.2007, Bozdag C.E. et al. 2003, zkan G. Büyu"ko“" et al.2004, Chan F.T.S. et al.2007).

\section{Fuzzy AHP and AHP}

Traditional approach of AHP have some inadequacies like (Kabir \& Hasin, 2011b)largely AHP method is used in closely crisp decision applications, it deals with an unstable scale of judgment, it does not take into account the ambiguity accompanying with the representation of one's decision to a number, selection and inclination of decision-makers have great impact on the results of AHP. Moreover, human assessment on qualitative traits is always subjective and hence indefinite. Consequently, conventional AHP appears insufficient to capture the expectation of decision maker(Kabir \& Hasin, 2011b). In view of the same, fuzzy sets could be combined with the pair wise comparison as an addition of AHP. Fuzzy AHP, helps to overcome the incompetence of AHP in managing linguistic variables. The fuzzy AHP tactic lets more exact explanation of the judgment making process.

\section{Fuzzy analytic hierarchy process}

Zadeh in 1965 was the first who make us all familiar with Fuzzy Set Theory and how it helps in handling the data which is ambiguous and unclear in nature. The most important support of Fuzzy set theory is the skill of presenting the data which is indefinite. The fuzzy AHP method is an advanced analytical method which reflects the uncertain preferences of decision maker through crisp values. One can reach to priorities with various methods of Fuzzy like geometric mean method (Buckley, 1985), extend analysis (Chang, 1996), fuzzy least square method (Xu, 2000).In 1992, Chan presented a new method for pair-wise comparison shadowed by practice of extent analysis method (Chang, 1996). The fuzzy evaluation matrix was built from the pair wise comparison of factors to the overall objective using the linguistic variables and triangular fuzzy numbers (Table 1)

Table1. Linguistic variables and Triangular Fuzzy Scale

\begin{tabular}{|c|c|c|c|c|}
\hline $\begin{array}{c}\text { Linguistic } \\
\text { Scale for } \\
\text { importance }\end{array}$ & $\begin{array}{c}\text { Fuzzy } \\
\text { Number } \\
\mathrm{s}\end{array}$ & Membership Functions & Domain & $\begin{array}{c}\text { Triangular } \\
\text { fuzzy } \\
\text { scale (I, } \\
\mathrm{m}, \mathrm{u})\end{array}$ \\
\hline Just Equal & $\tilde{1}$ & $\mu_{M}(x)=(3-x)$ & $1 \leq \mathrm{x} \leq 3$ & $(1,1,1)$ \\
\cline { 3 - 5 } & & & $1 \leq x \leq$ & $(1,3,5)$ \\
\hline $\begin{array}{c}\text { Equally } \\
\text { Important } \\
\text { Impakly }\end{array}$ & & 3 & \\
\hline
\end{tabular}




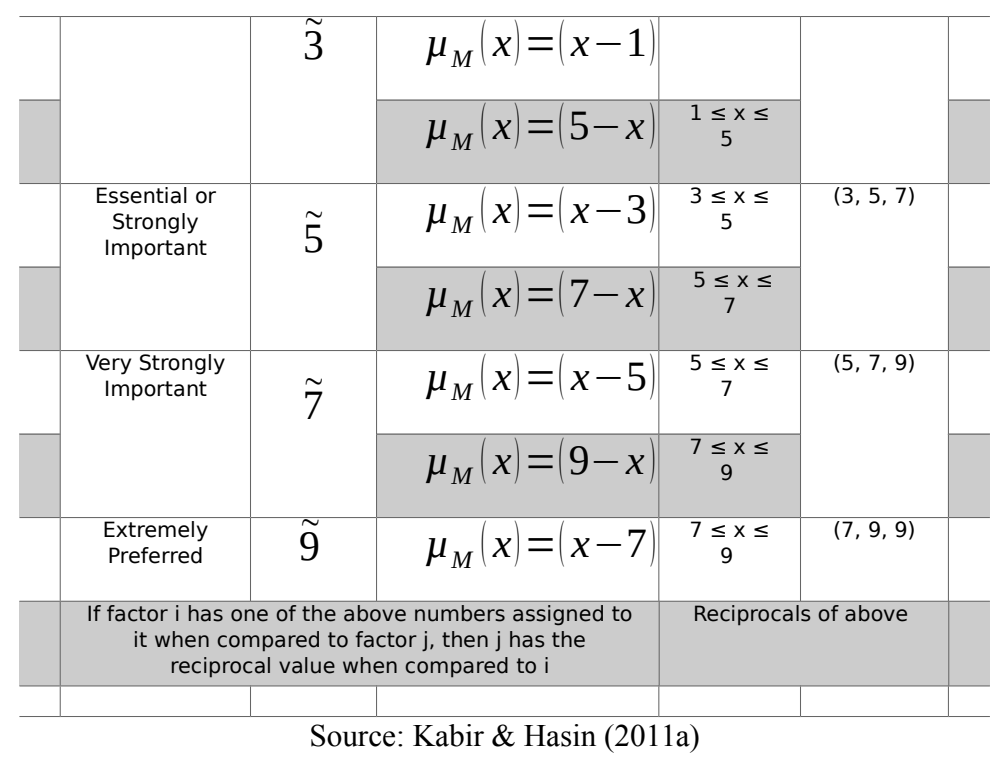

As per Chang $(1992,1996)$ each object is to be considered and analyzed for each goal so that extent analysis values for each object can be achieved. Fuzzy set is defined by membership function where the fuzzy logic helps in defining the real word situations to "moderate" or, "high" or "low" in place of "true /false", which range from zero and one (Kahraman et al. 2002, Shu, M. S et al.2006)

\section{Application of the models}

To authorize the proposed model, it is executed for the consumer who is regular buyer of staple food commodity, wheat flour, where the initial survey instrument was pretested by 12 consumers and 8 retailers. Consumers and retailers also proposed improvements to the questionnaire. According to the feedback and the comments from the retailers and consumers, the questionnaire was revised. A formal empirical survey was then conducted within a span of three weeks, and the total number of useful responses collected was 200. Out of this population, a sample of 200 respondents, in equal proportion, was selected from three different residential localities, on the basis of convenience. The respondents were contacted at their households and the data was collected by personally interviewing the selected respondents with the help of a structured questionnaire. We ask them to simply compare these three stages with respect to fundamental scale given by Saaty (1977) shown in Table 1

Table 1. Thomas L. Satty's Scale for Analytical Hierarchy Process:

\begin{tabular}{|c|c|c|}
\hline Scale & Definition & Explanations \\
\hline 1 & Equally preferred & Equal Importance \\
\hline 2 & Equally to moderately preferred & \\
\hline 3 & Moderately preferred & Weak Importance of one over another \\
\hline & & \\
\hline 4 & Moderately to strongly preferred & \\
\hline
\end{tabular}




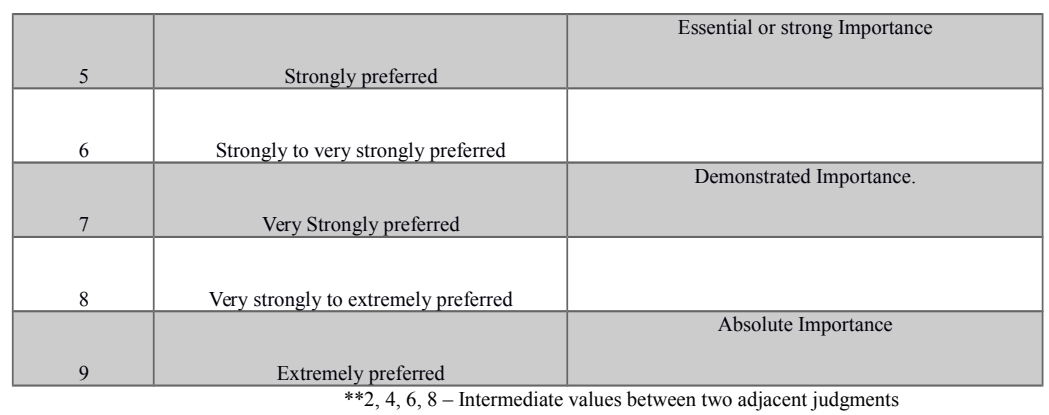

The membership of fuzzy class is well-defined by three characters $(1, \mathrm{~m}, \mathrm{u})$ which represents the minimum value, favorable value and highest value. The comparison matrix demonstrated

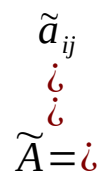

Where $\tilde{a}_{i j}=\left(l_{i j}, m_{i j}, u_{i j}\right)=\tilde{a}_{j i}^{-1}=\left(\frac{1}{u_{j i}}, \frac{1}{m_{j i}}, \frac{1}{l_{j i}}\right)$ for $i, j=1, \ldots . . n \wedge i \neq j$

Because our respondents are direct customer, it is difficult for us to make them understand the three well - defined members of fuzzy i.e. lower, upper and middle value. So, from each question the least value is taken as $(l)$, the highest value as $(u)$ and themodel value as $(m)$ .Then fuzzified comparison matrix was developed as:

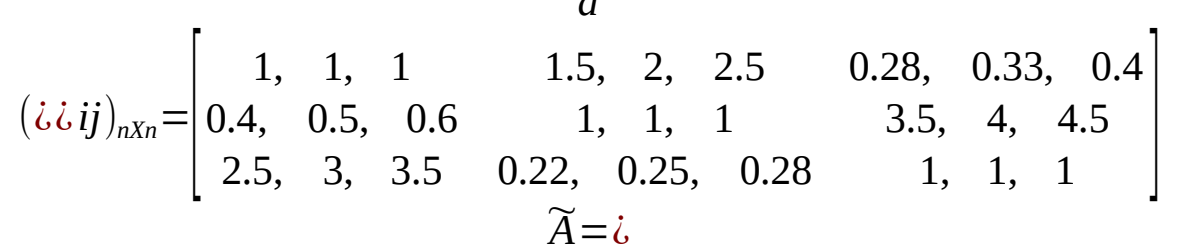

We calculated the priority vector as proposed by Chang D.Y. in 1996 where we first calculated $\widetilde{A}$ by fuzzy arithmetic operations

$$
R S_{i}=\sum_{j=1}^{n} \tilde{a}_{i j}=\left(\sum_{j=1}^{n} l_{i j}, \sum_{j=1}^{n} m_{i j}, \sum_{j=1}^{n} u_{i j}\right), i=1, \ldots, n
$$

And, then normalized the row by the correct normalization formula proposed by Wang YingMing (2008) 


$$
\left.\widetilde{S}_{i}=\frac{R S_{i}}{\sum_{j=1}^{n} R S_{j}}=\mid \frac{\sum_{j=1}^{n} l_{i j}}{\sum_{j=1}^{n} l_{i j}+\sum_{k=1, k \neq i}^{n} \sum_{j=1}^{n} m_{k j}}, \frac{\sum_{j=1}^{n} m_{i j}}{\sum_{k=1}^{n} \sum_{j=1}^{n} m_{k j}}, \frac{\sum_{j=1}^{n} u_{i j}}{\sum_{k=1}^{n} u_{i j}+\sum_{k=1, k \neq 1}^{n} \sum_{j=1}^{n} l_{k j}}\right), i=1, \ldots n
$$

Then calculated the degree of possibility $\tilde{S}_{i} \geq \widetilde{S}_{j}$ which acts as an elastic constraint on the values that may be assigned to a variable. Where $\tilde{S}_{i}=\left(l_{i}, m_{i}, u_{i}\right) \wedge \tilde{S}_{j}=\left(l_{j}, m_{j}, u_{j}\right)$

$$
V\left(\widetilde{S}_{i} \geq \widetilde{S}_{j}\right)=\left\{\begin{array}{cc}
1, & \text { if } m_{i} \geq m_{j} \\
\frac{u_{i}-l_{j}}{\left(u_{i}-m_{i}\right)+\left(m_{j}-l_{j}\right)}, & \text { if } l_{j} \leq u_{i} \\
0, & \text { others }
\end{array}\right.
$$

And finally, defined the priority vector $W=\left(w_{1}, \ldots, w_{n}\right)^{T}$ of fuzzy comparison matrix $\widetilde{A}$

$$
w_{i}=\frac{V\left(\widetilde{S}_{i} \geq \widetilde{S}_{j} \vee j=1, \ldots \ldots . . n ; j \neq i\right)}{\sum_{k=1}^{n} V\left(\widetilde{S}_{k} \geq \widetilde{S}_{j} \vee j=1, \ldots ., n ; j \neq k\right)}, i=1, \ldots . ., n .
$$

The degree of possibility of dominance of $S_{i}$ is calculated and is represented by $V\left(\widetilde{S}_{i} \geq \widetilde{S}_{j}\right)$. Therefore, the degree of possibilityfor the first (IS) constraint-

$$
\begin{aligned}
& V\left(S_{I S} \geq S_{E S}\right)=1 \\
& V\left(S_{I S} \geq S_{P S}\right)=0.372
\end{aligned}
$$

the degree of possibility for the second (ES) constraint-

$$
\begin{aligned}
& V\left(S_{E S} \geq S_{I S}\right)=1 \\
& V\left(S_{E S} \geq S_{P S}\right)=1
\end{aligned}
$$

the degree of possibility for the third (PS) constraint- $V\left(S_{P S} \geq S_{I S}\right)=1$

$$
V\left(S_{P S} \geq S_{E S}\right)=0.194
$$


If considering Fuzzy weight of the original comparison matrix A, $\lambda_{\max }=3.805$ with CI $=0.40727$ which is better than the additive and reduced the error by fifty percent and the final weights are $\left(\begin{array}{lll}0.238 & 0.638 & 0.124\end{array}\right)$ for IS, ES and PS respectively.

\section{Conclusion}

In this study of analyzing the Buyer Decision Process for wheat flour the staple food commodity, we have explored the three stages Information stage, Evaluation Stage and Purchase Stage. Information Stage is habitually the initiative phase where consumer actually become aware of the competing brands either through friends/retailers/relatives/point of purchase. At Evaluation Stage consumer assess the information collected in the Information Search from the alternatives available in particular category through nutrition, taste, free from adulterant/insecticide, quality. And finally at Purchase Stage consumer make final decision to buy the particular product. So, the answer to the question that how does consumer selects from the alternatives. Answer lies in the fact that there are various factors at each stage which influence the consumer to buy one product over the other and this process vary from individual to other depending upon his/her buying situation. A consumer may buy a brand based on a single attribute, or a number of them. If during the Evaluation Stage companies are able to give a reason to the customer to buy it would be easy to predict the buying behavior more accurately. Marketers must study buyers to discover how they actually evaluate brand alternatives. To attain maximum customer, company should focus more to influence the buyer at Evaluation Stage.

Various Multicriteria decision making methods constructed on the linguistic estimations like AHP supports to create the finest decision within the current options through pair wise comparisons. Nevertheless for the undefined or fuzzy environment, FAHP method confirmed to be a useful method in attempting real-world multi-criteria decision making problems. Fuzzy AHP method was used to combine the estimations of the decision makers to classify the weight for each criterion. It confirmed that the ambiguity in human thinking can be solved through an organized mode and a simple process.

\section{$\underline{\text { References }}$}

1. Bellenger, D N and P.K.Koragaonkar , 1980. Profiling the recreational shopper. Jouranl of Retailing 6, 77-92.

2. C.E. Bozdag , C. Kahraman, D. Ruan, Fuzzy group decision making for selection among computer integrated manufacturing systems, Computers in Industry 51 (2003) 13-29.

3. C.G.E. Boender, J.G. de Graan \& F.A. Lootsma, (1989) "Multi-criteria decision analysis with fuzzy pairwise comparisons”, Fuzzy Sets and Systems, 29(2), 133-143. 
4. Cox ,D.F.(ed.) ,1967.Risk taking and information handling in consumer behavior, Divison of research, Graduate School of Business , Harvard University.

5. D.Y. Chang, (1992) "Extent analysis and synthetic decision", Optimization Techniques and Applications, 1, 352-355.

6. D.Y. Chang, (1996) "Applications of the extent analysis method on fuzzy AHP", European Journal of Operational Research, 95(3), 649-655.

7. D.Y. Chang, Applications of the extent analysis method on fuzzy AHP, European Journal of Operational Research 95 (1996) 649- 655

8. F.T. Bozbura, A. Beskese \& C. Kahraman, (2007) "Prioritization of human capital measurement indicators using fuzzy AHP”, Expert Systems with Applications, 32(4), 1100-1112.

9. F.T. Bozbura, A. Beskese, Prioritization of organizational capital measurement indicators using fuzzy AHP, International Journal of Approximate Reasoning 44 (2007) 124-147

10. F.T.S. Chan, N. Kumar, Global supplier development considering risk factors using fuzzy extended AHP-based approach, Omega 35 (2007) 417-431.

11. G. Bu"yu"ko"zkan, T. Ertay, C. Kahraman, D. Ruan, Determining the importance weights for the design requirements in the house of quality using the fuzzy analytic network approach, International Journal of Intelligent Systems 19 (2004) 443-461.

12. G. Kabir \& M.A.A. Hasin, (2011) "Evaluation of Customer Oriented Success Factors in Mobile Commerce Using Fuzzy AHP", Journal of Industrial Engineering and Management, 4(2), 361386.

13. Hansen, F., 1972 .Consumer Choice Behaviour: A Cognitive theory,New York :The Free Press.

14. Howard N.Sheth and J.A.Howard ," The Theory of Buyer Beh., Willey :1969

15. HOWARD, J. A. (1994),Buyer Behavior in Marketing Strategy,2nd edition, New Jersey, Prentice Hall.

16. J.J. Buckley, Fuzzy hierarchical analysis, Fuzzy Sets and Systems 17 (1985) 233-247

17. L. Mikhailov, Deriving priorities from fuzzy pairwise comparison judgments, Fuzzy Sets and Systems 134 (2003) 365-385.

18. Lilien,G.L., P. Kotler and K.S. Moarlhy (1992). Marketing Model. PrenticeHall, Englcwaod Cliffs, NJ

19. Mittelstaedt, R.A., S.L. Grossbart, W.W.Curtis, and S.P. Devere, 1976. Optimum simulation level and the adoption decision process. Journal of Consumer research 3, 84-94.

20. Price. L.L. and N.M. Ridgway, 1982. Use innovation, vicarious exploration and purchase explration:Three facets of consumer varied behaviours .In:B .J.Walker et.al.(eds.),1982 Educators 'Conference Proceedings' ,50-60,Chicago, IL:American Marketing Associatins. 
21. R. Csutora, J.J. Buckley, Fuzzy hierarchical analysis: The Lamda-Max method, Fuzzy Sets and Systems 120 (2001) 181-195.

22. R. Xu, Fuzzy least-squares priority method in the analytic hierarchy process, Fuzzy Sets and Systems 112 (2000) 359-404.

23. Saaty T (1977). A scaling method for priorities in hierarchical structures. J Math Psychol 15: 234-281.

24. Saaty T (1980). The Analytic Hierarchy Process. McGraw-Hill: New York.

25. Sheth J.N., B.I.Newman, and B.LGross, 1991. Consumption values and Market Choices:Theory and Applications,Linncinnati, $\mathrm{OH}$ : South Western Publishing.

26. Venkatraman, M.P. and L.L. Price, 1990. Differentiating between cognitive and sensory innovativeness: Concepts, Measurement and implications. Journal of Business Research 20, 293-315.

27. Y.M. Wang, T.M.S. Elhag, on the normalization of interval and fuzzy weights, Fuzzy Sets and Systems 157 (2006) 2456-2471. 